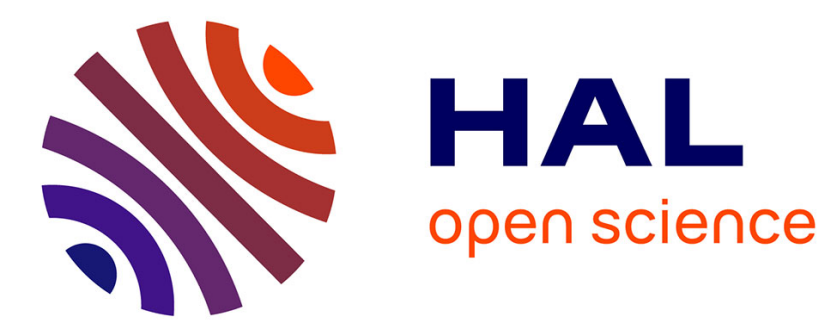

\title{
Gain Enhancement of a Dielectric Resonator Antenna Using a Cylindrical Electromagnetic Crystal Substrate
} Yacouba Coulibaly, Halim Boutayeb, Tayeb Denidni

\section{To cite this version:}

Yacouba Coulibaly, Halim Boutayeb, Tayeb Denidni. Gain Enhancement of a Dielectric Resonator Antenna Using a Cylindrical Electromagnetic Crystal Substrate. IEEE Antennas and Propagations Symposium 2007, Jun 2007, Honolulu, United States. pp.1325-1328. hal-00156630

\section{HAL Id: hal-00156630 https://hal.science/hal-00156630}

Submitted on 22 Jun 2007

HAL is a multi-disciplinary open access archive for the deposit and dissemination of scientific research documents, whether they are published or not. The documents may come from teaching and research institutions in France or abroad, or from public or private research centers.
L'archive ouverte pluridisciplinaire HAL, est destinée au dépôt et à la diffusion de documents scientifiques de niveau recherche, publiés ou non, émanant des établissements d'enseignement et de recherche français ou étrangers, des laboratoires publics ou privés. 


\title{
Gain Enhancement of a Dielectric Resonator Antenna Using a Cylindrical Electromagnetic Crystal Substrate
}

\author{
Yacouba Coulibaly, Halim Boutayeb, and Tayeb A. Denidni \\ INRS-EMT, University of Quebec, Montreal, Canada. \\ Couli@emt.inrs.ca
}

\section{Introduction}

Over the last decades, an increasing attention has been paid to the investigation of Dielectric Resonator Antennas [1-3] due to their attractive features. DRAs have several advantages, such as low losses, high radiation efficiency, high integration, and reduced size. However, one drawback of the DRA is its low gain characteristics. Few studies have been reported to improve the radiation characteristics of the DRA. In [4], a rectangular DRA is placed on different ground plane shapes (coaxially corrugated, strip corrugated and mushroom-like Electromagnetic Band Gap (EBG) substrate) to suppress the surface wave modes. In this communication, we present a new substrate to reduce the surface waves and to increase the gain of a dielectric resonator antenna. In $[5,6]$, circularly periodic Electromagnetic Band Gap (EBG) substrates have been designed in order to enhance the performance of printed dipoles antennas and microstrip slot antennas. The advantage of the circularly symmetric geometries is that a surface wave generated by a source located at its center experiences the same bandgap effect in all radial directions. Using this concept, a new EBG substrate is introduced to increase the gain of a cylindrical Dielectric Resonator Antenna. The proposed EBG substrate is based on the mushroom-like structure [7] and is constructed as a combination of two periodic structures. One periodic structure is composed of metal rings and the other is constituted of vertical metal vias, which are disposed such as to form a radially and circularly periodic structures. The disposition of the vias is based on the analysis proposed in [8].

\section{Numerical results}

A cylindrical Dielectric Resonator Antenna and its cylindrical EBG substrate were designed by using the Finite Element method (HFSS-Ansoft [9]). In the simulation process, convergence and minimization of errors were obtained by ensuring that enough iterations were used. Figure 1 shows the schematic of the proposed DRA surrounded by a cylindrical structure composed of metal rings and grounding vias. The dielectric resonator antenna has a radius $R$ of $15 \mathrm{~mm}$, a height $h_{d}$ of $10.5 \mathrm{~mm}$ and a dielectric constant $\varepsilon_{D R A}$ of 31.5. The lowest mode $H E M_{11 \delta}$ is excited. The dielectric antenna is feed via a coaxial line, which is at the distance $11 \mathrm{~mm}$ from the center.

The circularly symmetric EBG structure is composed of strips and metallic vias. The concentric rings of strips are printed on a substrate with a relative permittivity of $\varepsilon_{r}=2.2$ and thickness $h=3.2 \mathrm{~mm}$ (Rogers RT/Duroid 5880). In the horizontal plane, the substrate occupies a square of larger $154 \mathrm{~mm}$. The distance from one strip to another is $g=2 \mathrm{~mm}$, and the radial period is $P_{r 1}=24.6 \mathrm{~mm}$. The first metal ring starts at the radius $R+g$, so that the beginnings of the strips are $b+g+(n-1) P_{r 1}$. The vias have the radius $a=2 \mathrm{~mm}$, and they are disposed with the same transversal period $P_{t}=P_{r 2} \pi / 6$ and the same radial period $P_{r 2}=23.6 \mathrm{~mm}$. The optimized radial periods are close to $\lambda / 4$. According to [8], when the transversal period $P_{t}$ is kept constant, the cylindrical periodic structure of metallic vias act as a lattice of inductances 
to cylindrical waves. The strips act as a lattice of capacitances. The EBG substrate is then the equivalent of the mushroom-like substrate [7] with a circular symmetry.

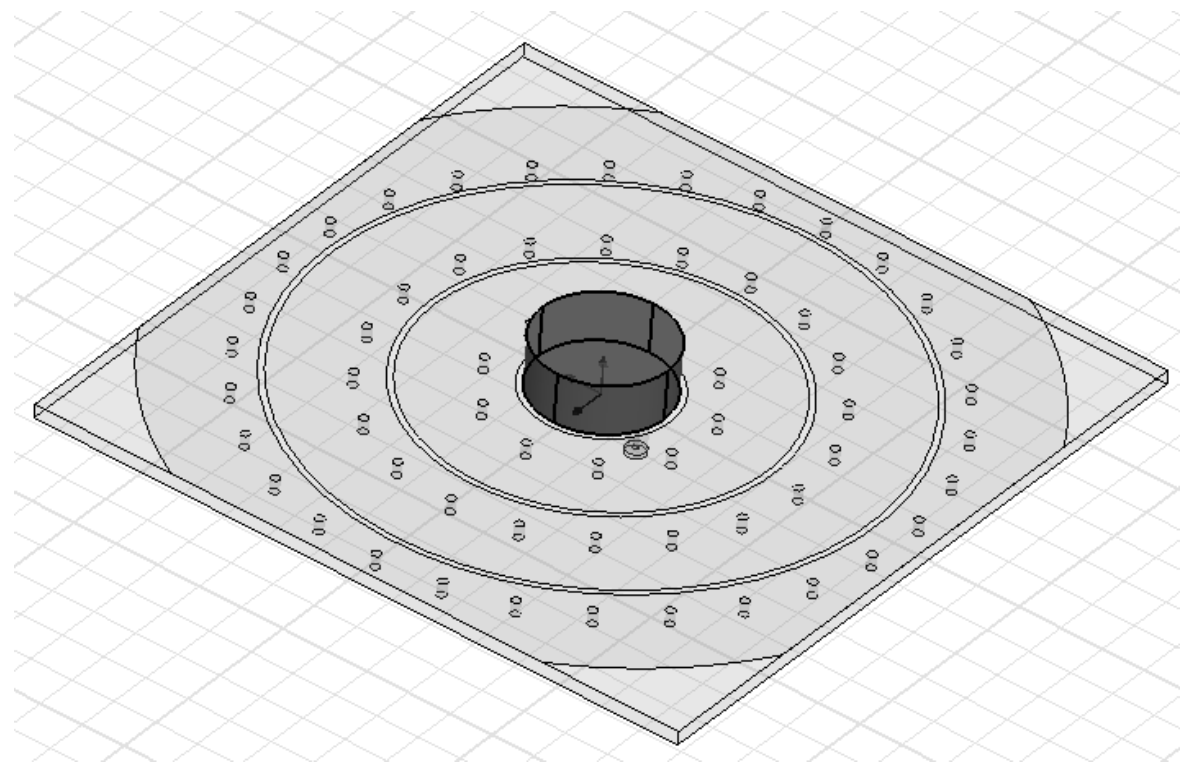

Figure 1: Dielectric Resonator Antenna Surrounded by a cylindrical EBG substrate.

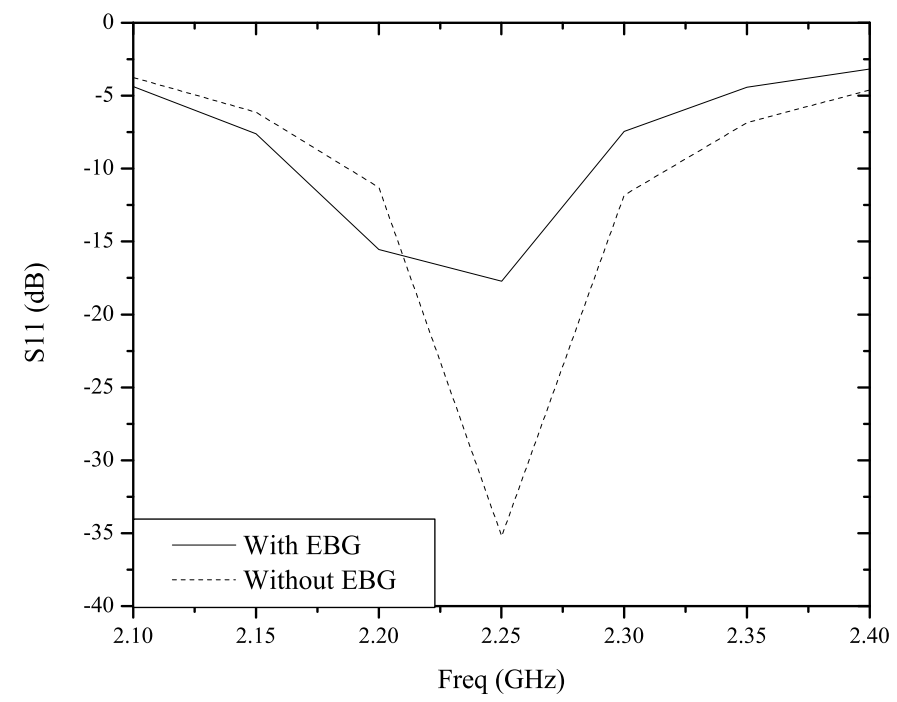

Figure 2: Simulated return loss of the antenna, with and without the EBG substrate.

Figure 2 shows the simulated return loss of the DRA with classical substrate (without the strips and vias) and of the DRA with the EBG substrate. The matching $\left(S_{11}<-10 \mathrm{~dB}\right)$ of the antenna is obtained around $2.25 \mathrm{GHz}$ for both cases. Figure 3 shows the simulated gain of the antenna, with and without the EBG structure. From these curves, the new substrate allows to increase the gain by $3 d B$, due to the reduction of the surface waves. Figure 4 presents the radiation patterns in both $\mathrm{H}$ - and E- planes, at $2.25 \mathrm{GHz}$, showing that the back lobes radiations are reduced thanks to the EBG substrate. 


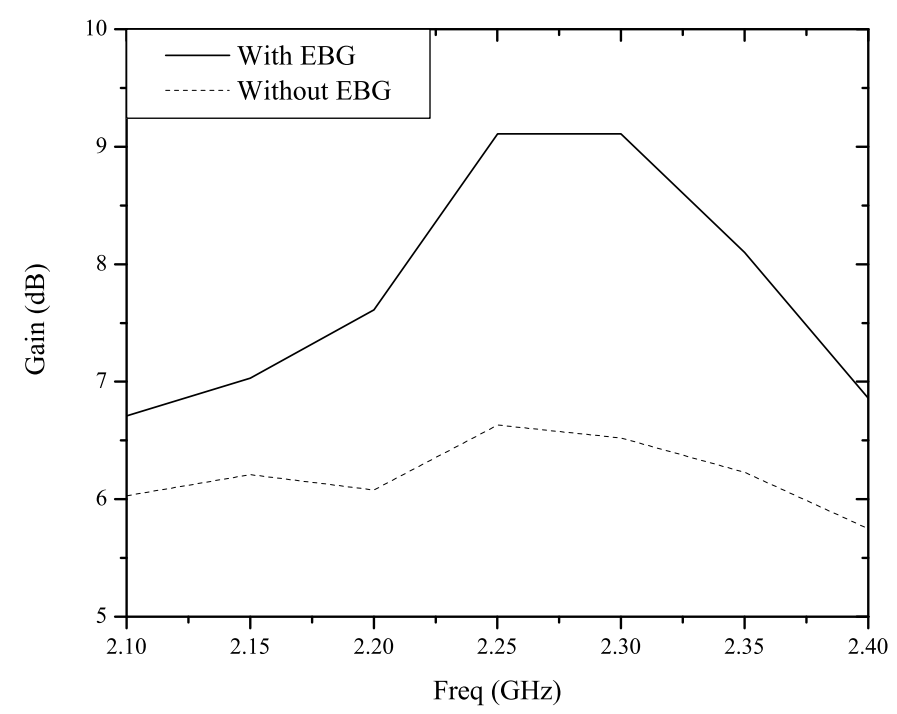

Figure 3: Simulated gain of the antenna, with and without the EBG substrate.

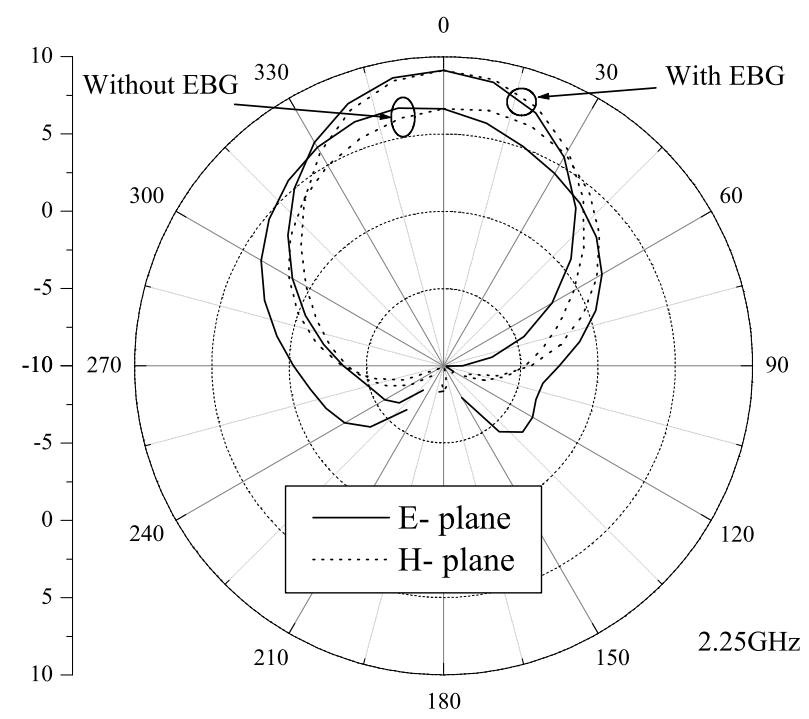

Figure 4: Radiation patterns at $2.25 \mathrm{GHz}$, in both $\mathrm{H}$ - and E- planes, with and without the EBG substrate.

\section{Conclusion}

In this paper, a novel technique for the gain enhancement of Dielectric Resonator Antennas using a cylindrical EBG structure has been proposed and demonstrated numerically. The analysis and design of the structure has been based on the fact that the surface wave propagation is reduced in all radial directions thanks to the circular symmetry of the proposed EBG structure. The EBG structure is based on the mushroom-like structure with a circular symmetry. It is composed of a periodic 
structure of metallic rings and of a periodic structure of vias. The periods of these two structures have been optimized using a full wave method to maximize the antenna gain. Numerical results have been presented showing that a gain enhancement of 3 $d B$ is achieved with the new substrate. Experimental results will be presented during the conference.

\section{Acknowledgment}

The authors gratefully acknowledge the support of this research from National Science Engineering Research Council of Canada (NSERC).

\section{References}

[1] R. K. Mongia and P. Bhartia, "Dielectric resonator antennas - a review and general design relations for resonant frequency and bandwidth", International Jour. Microwave and Millimeter-Wave Computer-Aided Engineering, vol. 4, no. 3, pp. 230-247, 1994

[2] R. K. Mongia, A. Ittipibon and M. Cuhaci, "Measurement of radiation efficiency of dielectric resonator antennas", IEEE Microwave Guided Wave Letters, vol. 4, no.3, pp. 80-82, March 1994

[3] K.M. Luk and K.W. Leung, Dielectric Resonators Antennas, Research Studies Press Ltd., Hertfordshire, UK, 2002.

[4] E. El-Deen, S. H. Zeinud-Deen, H.A. Sharshar, M.A. Binyamin, "The effect of ground plane shape on the characteristics of rectangular dielectric resonator antennas", in Proc. IEEE AP-S Int. Symp. Dig., pp. 3013- 3016, July 2006.

[5] N. Llombart, A. Neto, G. Gerini, and P. de Maagt, "Planar circularly symettric EBG structures for reducing surface waves in printed antennas", IEEE Trans. Antennas Propag., vol. 53, pp. 3210-3218, Oct. 2005.

[5] A. Neto, N. Llombart, G. Gerini, and P. de Maagt, "On the optimal radiation bandwith of ptinted slot antennas surrounded by EBGs", IEEE Trans. Antennas Propag., vol. 543, pp. 1074-1083, Ap. 2006.

[7] D. Sievenpiper, L. Zhang, R.F. Jimenez Broas, N. G. Alexopoulos, and E. Yablonovitch, "High-impedance electromagnetic surfaces with a forbidden frequency band", IEEE Tran. Microw. Theo. Techn., vol. 47, pp. 2059-2074, Nov. 1999.

[8] H. Boutayeb, K. Mahdjoubi, and A.C. Tarot, "Analysis of radius-periodic cylindrical structures", in Proc. IEEE AP-S Int. Symp. Dig., vol. 2, pp. 813- 816, June 2003.

[9] HFSS, v. 9, User Guide, Ansoft Coorporation, Pittsburg, USA. 